\title{
Correction to: Smoking Policy Change Within Permanent Supportive Housing
}

\author{
Anne Berit Petersen ${ }^{1} \cdot$ Holly C. Stewart ${ }^{2} \cdot$ Jon Walters $^{3} \cdot$ Maya Vijayaraghavan $^{4}$
}

Published online: 7 April 2018

(c) Springer Science+Business Media, LLC, part of Springer Nature 2018

Correction to: J Community Health (2018) 43:312-320 https://doi.org/10.1007/s10900-017-0423-7

The original version of this article unfortunately contains mistakes.

1. On page 315, in the last sentence under the "Tobacco Use" subheading, the percentage should read "59.3\%" rather than " $55.6 \%$ ".

2. On page 315, in the last sentence under the "Secondhand Smoke Exposure" subheading, the percentage " $28.2 \%$ " should read " $28.6 \%$ ".

3. The presentation of "Post-policy" and "Pre-policy" terms in the Figs. 1 and 3 were incorrect.

It should be read as:

Figure 1: Pre-policy $(n=27)$; Post-policy $(n=16)$.

Figure 3: Pre-policy $(n=55)$; Post-policy $(n=42)$.

The corrected Figs. 1 and 3 are given below.

The original article can be found online at https://doi.org/10.1007/ s10900-017-0423-7.

Maya Vijayaraghavan

Maya.Vijayaraghavan@ucsf.edu

1 School of Nursing, Loma Linda University, Loma Linda, CA, USA

2 Department of Epidemiology, University of California Berkeley, Berkeley, CA, USA

3 Housing Innovation Partners, San Diego, CA, USA

4 Division of General Internal Medicine/Zuckerberg San Francisco General Hospital, School of Medicine, University of California San Francisco, 1001 Potrero Ave, Box 1364, San Francisco, CA 94110, USA 
Fig. 1 Current smokers anticipated and reported responses to "proposed" and "current" smoke-free policy. Percent change (95\% CI) (a) - $11.0 \%$ $(-40.3,18.3)$; (b) $-14.9 \%$ $(-47.1,17.3) ;(\mathrm{c})-1.5 \%$ $(-28.1,25.0)$; (d) $13.8 \%$ $(-13.8,41.5)$

Fig. 3 Attitudes towards "proposed" and "current" smoke-free policy in pre- and post-implementation samples. Percent change $(95 \%$ CI): (a) 7.5\% (-12.0, 27.0); (b) 10.3 $(-9.3,29.8)$; (c) $18.7 \%(0.1$, $36.7)$
"I would try [I tried] to stop smoking completely because of the policy"(a)

"I would try to quit [I quit] smoking for a short time because of the policy"(b)...

"I would try to cut down [I cut down] on my smoking because of the policy"(c)

"I think I would be [I am] much more irritable because of the policy"(d)

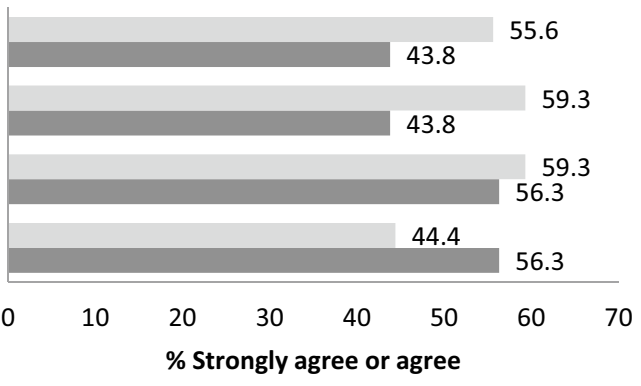

Pre-policy $(n=27) \quad \square$ Post-policy $(n=16)$

"I would choose to live in a facility that had a policy that restricted smoking indoors"(a)

"I am happy to stay on this property because of the proposed [current] policy"(b)

"I support the proposed [current] policy"(c)

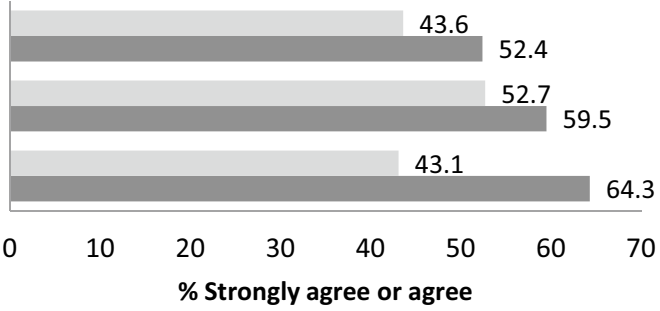

Pre-policy $(n=55) \quad$ Post-policy $(n=42)$ 